\title{
Long-term loss of color vision after exposure to mercury vapor
}

C. Feitosa-Santana ${ }^{1,2}$,

M.F. Costa ${ }^{1}$, M. Lago ${ }^{2}$ and D.F. Ventura ${ }^{1,2}$
${ }^{1}$ Departamento de Psicologia Experimental, Instituto de Psicologia, ${ }^{2}$ Núcleo de Neurociências e Comportamento, Universidade de São Paulo, São Paulo, SP, Brasil

\author{
Correspondence \\ C. Feitosa-Santana \\ Departamento de Psicologia \\ Experimental, IP, USP \\ Av. Prof. Mello Moraes, 1721 \\ Bloco A, Sala D9 \\ 05508-900 São Paulo, SP \\ Brasil \\ E-mail: claudia@feitosa-santana.com \\ Presented at the Symposium on \\ Sensory and Neuropsychological \\ Losses Due to Mercury Intoxication \\ and to Other Neurodegenerative \\ Processes. Studies in Humans and \\ in Animal Models. Águas de Lindóia, \\ SP, Brazil, August 25-29, 2004. \\ Research supported by FAPESP \\ (Projeto Temático No. 02/12733-8 \\ to D.F. Ventura), CNPq (No. \\ 480897/2004-2), and CAPES \\ (PROCAD No. 0019/01-1). \\ C. Feitosa-Santana is the recipient \\ of a FAPESP doctoral fellowship and \\ D.F. Ventura is the recipient of a \\ CNPq $1 \mathrm{~A}$ research fellowship.
}

Received June 6, 2006 Accepted October 18, 2006 $\ldots \ldots \ldots \ldots \ldots \ldots \ldots$

\section{Abstract}

We evaluated the color vision of 24 subjects ( $41.6 \pm 6.5$ years; 6 females) who worked in fluorescent lamp industries. They had been occupationally exposed to mercury vapor $(10.6 \pm 5.2$ years $)$ and had been away from the source of exposure for $6.4 \pm 4.04$ years. Mean urinary concentration of mercury was $40.6 \pm 36.4 \mu \mathrm{g} / \mathrm{g}$ creatinine during or up to 1 year after exposure and $2.71 \pm 1.19 \mu \mathrm{g} / \mathrm{g}$ creatinine at the time of color vision testing or up to 1 year thereafter. All patients were diagnosed with chronic mercury intoxication, characterized by clinical symptoms and neuropsychological alterations. A control group $(\mathrm{N}=36,48.6 \pm 11.9$ years, 10 females, $1.5 \pm 0.47 \mu \mathrm{g}$ mercury/g creatinine) was subjected to the same tests. Inclusion criteria for both groups were Snellen VA 20/30 or better and absence of known ophthalmologic pathologies. Color discrimination was assessed with the Farnsworth D-15 test (D-15) and with the Lanthony D-15d test (D15d). Significant differences were found between the two eyes of the patients $(\mathrm{P}<0.001)$ in both tests. Results for the worst eye were also different from controls for both tests: $\mathrm{P}=0.014$ for $\mathrm{D}-15$ and $\mathrm{P}<0.001$ for D-15d. As shown in previous studies, the D-15d proved to be more sensitive than the D-15 for the screening and diagnosis of the color discrimination losses. Since color discrimination losses were still present many years after the end of exposure, they may be considered to be irreversible, at least under the conditions of the present study.
Key words

- Color vision

- Chromatic discrimination

- Color discrimination

- Psychophysics

- Mercury intoxication

- Occupational exposure
Color vision losses in workers exposed to metallic mercury and some solvents have been demonstrated to be an indicator of the subclinical effect of exposure to neurotoxicants (1-5), revealing effects at exposure levels below the threshold level limits adopted by organizations in different countries. These studies suggest the need for the discussion of the values currently established for occupational limits of exposure considered safe.
Changes in visual performance associated with environmental exposure to mercury have also been assessed in other visual functions besides color vision, such as contrast sensitivity, visual field, visual evoked potentials, and electroretinogram (3-5). The objective of the present study was to evaluate the effect of long-term exposure to mercury on color vision.

Color vision was assessed with the Lan- 
thony D-15d test (D-15d) and the Farnsworth D-15 test (D-15) was also used to screen for congenital defects in both controls and patients. In a previous study (4), the D-15d results were described in a very summarized form, since other color vision tests and types of assessment were the subject of that publication. Since the D-15d test is extensively used in clinical practice and is also convenient for field work in research on color vision due to its portability and accessible cost, we re-examined its usefulness here for the assessment of color vision losses in this group of workers who had been exposed to mercury vapor.

The D-15d test was designed by Lanthony in 1978 for screening acquired color vision loss $(6,7)$ and has been frequently used in neurotoxicologic examinations of the effects of exposure to solvents and other occupational or environmental toxicants $(1-4,8)$. The D-15 test was designed by Farnsworth in 1943 for screening congenital and acquired color vision deficiencies and is effective in separating subjects with severe congenital deficiencies from normal and slightly defective observers $(9,10)$.

In the present study, we measured the color discrimination of 24 subjects (41.6 \pm 6.5 years; 6 females) with $7.96 \pm 2.1$ years of education, previously exposed to mercury vapor as workers in fluorescent lamp factories. The mean duration of exposure was $10.6 \pm 5.2$ years (range: 4 to 24.5 years) and the mean time away from that occupational environment was $6.4 \pm 4.04$ years (range: 1 to 15 years). Mean urinary $\mathrm{Hg}$ concentration was $40.6 \pm 36.4 \mu \mathrm{g} / \mathrm{g}$ creatinine (range: 1.2 to $134.7 \mu \mathrm{g} / \mathrm{g}$ creatinine) during or up to 1 year after exposure and $2.71 \pm 1.19 \mu \mathrm{g} / \mathrm{g}$ creatinine (range: $<1$ to $4.3 \mu \mathrm{g} / \mathrm{g}$ creatinine) during or up to 1 year after the color vision tests (Table 1). Exclusion criteria were the presence of ophthalmologic or neurophthalmologic symptoms, history of psychiatric disorders before the occupational exposure to mercury, exposure to other heavy metals or to mercury prior to admission to fluorescent lamp industries, diabetes, alcoholism, and smoking (more than 5 cigarettes per day).

The subjects were referred by the Department of Legal and Occupational Medicine of the Oscar Freire Institute, University of São Paulo, São Paulo, SP, Brazil. All had been formerly discharged from work and placed on disability retirement due to a medical diagnosis of mercury intoxication based on clinical examination, neuropsychological evaluation, exposure history and urinary levels of mercury. Most had received clinical follow-up since 1997, with ophthalmologic exams, cranial tomography, and psychiatric and psychological treatment. In some patients the urinary levels of mercury had not been determined during, or shortly after, exposure to mercury. This lack of information was attenuated by two facts: all subjects came from three manufacturing factories, with very similar work and exposure conditions. Exposure ceased when the urinary level was more than $35 \mu \mathrm{g} \mathrm{Hg} / \mathrm{g}$ creatinine, the biological exposure index established by the American Conference of Governmental Industrial Hygienists (ACGIH) (11). The ACGIH considers $5 \mu \mathrm{g} \mathrm{Hg} / \mathrm{g}$ creatinine to be the biological exposure index for non-exposure.

Mercury intoxication is characterized by clinical symptoms such as renal impairment, oropharyngeal inflammation and neuromuscular changes (mostly tremors), as well as neuropsychological changes such as irritability, fatigue, loss of self-confidence, depression, anxiety, delirium, insomnia, apathy, loss of memory, headache, and general pain (12). Both classes of symptoms are present during chronic exposure and the clinical symptoms are commonly dose-related. The neuropsychological changes persist even after exposure is interrupted. In the present study, all patients examined reported loss of self-confidence and the other problems most often mentioned by at least $50 \%$ of the pa- 
tients were depression, fatigue, insomnia, and loss of memory.

Control subjects $(\mathrm{N}=36 ; 48.6 \pm 11.9$ years; 10 females) were tested with the same procedures for comparison. They were recruited from the staff and students of the University of São Paulo and were selected among healthy individuals matched by gender, age and years of education to the experimental subjects. Exclusion criteria were the same as described for the mercury-intoxicated group. Urinary mercury concentration was measured in 21 subjects at the time of color vision testing or up to 1 year thereafter.
Mean urinary concentration of $\mathrm{Hg}$ was $1.5 \pm$ $0.47 \mu \mathrm{g} / \mathrm{g}$ creatinine (range: $<1$ to $2.5 \mu \mathrm{g} / \mathrm{g}$ creatinine).

Before testing, an ophthalmologic examination was performed on each subject. The inclusion criteria for both patients and controls were Snellen VA 20/30 or better (Table 1) and absence of known ophthalmologic or other clinical diseases. Personal data, clinical history, past history of exposure, occupational history, and current diseases were recorded for each subject.

Informed consent was obtained from all subjects. The procedures complied with the

Table 1. Demographic information and color confusion index $(\mathrm{CCl})$ of the $\mathrm{D}-15 \mathrm{~d}$ test from the mercury-intoxicated group.

\begin{tabular}{|c|c|c|c|c|c|c|c|c|c|c|c|c|c|}
\hline ID & Sex & Age (years) & VA OD & VA OS & Exp. & Away & $\mathrm{Hg} 1$ & $\mathrm{Hg} 2$ & Best eye & Type & Worst eye & Type & Mean of eyes \\
\hline 1 & $M$ & 35 & $20 / 20$ & $20 / 25$ & 4.0 & 8.0 & 50.8 & 2.9 & 1.00 & & 1.00 & & 1.00 \\
\hline 2 & $\mathrm{~F}$ & 51 & $20 / 25$ & $20 / 25$ & 12.0 & 15.0 & & $<1$ & 1.38 & tritan & 1.41 & tritan & 1.39 \\
\hline 3 & M & 43 & $20 / 30$ & $20 / 25$ & 10.0 & 4.0 & 9.0 & $<1$ & 1.38 & tritan & 1.66 & tritan & 1.52 \\
\hline 4 & $\mathrm{~F}$ & 50 & $20 / 30$ & $20 / 30$ & 5.0 & 10.0 & & & 1.15 & tritan & 1.20 & tritan & 1.18 \\
\hline 5 & M & 47 & $20 / 20$ & $20 / 20$ & 10.0 & 4.0 & 28.8 & 4.3 & 1.00 & & 1.00 & & 1.00 \\
\hline 6 & M & 36 & $20 / 30$ & $20 / 30$ & 7.0 & 8.0 & & $<1$ & 1.00 & & 1.11 & & 1.06 \\
\hline 7 & $\mathrm{~F}$ & 40 & $20 / 20$ & $20 / 20$ & 11.0 & 2.0 & & $<1$ & 1.00 & & 1.04 & & 1.02 \\
\hline 8 & M & 35 & $20 / 20$ & $20 / 20$ & 10.5 & 7.5 & & $<1$ & 1.12 & & 1.12 & & 1.12 \\
\hline 9 & M & 35 & $20 / 20$ & $20 / 20$ & 7.0 & 6.0 & & $<1$ & 1.00 & & 1.16 & & 1.08 \\
\hline 10 & $M$ & 34 & $20 / 20$ & $20 / 20$ & 9.0 & 3.0 & 73.8 & 3.0 & 1.09 & & 1.10 & & 1.10 \\
\hline 11 & $M$ & 36 & $20 / 15$ & $20 / 15$ & 6.0 & 4.0 & & $<1$ & 1.00 & & 1.04 & & 1.02 \\
\hline 12 & $M$ & 47 & $20 / 20$ & $20 / 20$ & 13.0 & 1.0 & & & 1.00 & & 1.37 & tritan & 1.18 \\
\hline 13 & $M$ & 53 & $20 / 20$ & $20 / 15$ & 8.0 & 8.0 & 42.7 & & 1.00 & & 1.23 & tritan & 1.12 \\
\hline 14 & M & 41 & $20 / 20$ & $20 / 20$ & 24.5 & 1.0 & & & 1.00 & & 1.00 & & 1.00 \\
\hline 15 & $M$ & 54 & $20 / 20$ & $20 / 20$ & 14.0 & 12.0 & & 1.0 & 1.00 & & 1.28 & tritan & 1.14 \\
\hline 16 & $M$ & 43 & $20 / 20$ & $20 / 20$ & 12.0 & 12.0 & 56.6 & $<1$ & 1.20 & tritan & 1.39 & tritan & 1.29 \\
\hline 17 & $\mathrm{~F}$ & 36 & $20 / 20$ & $20 / 20$ & 8.5 & 2.0 & 1.2 & 2.8 & 1.27 & tritan & 1.27 & tritan & 1.27 \\
\hline 18 & $M$ & 43 & $20 / 20$ & $20 / 20$ & 12.0 & 6.0 & 66.0 & $<1$ & 1.00 & & 1.00 & & 1.00 \\
\hline 19 & $M$ & 33 & $20 / 25$ & $20 / 25$ & 5.0 & 2.0 & 2.4 & 1.3 & 1.00 & & 1.35 & tritan & 1.17 \\
\hline 20 & $F$ & 45 & $20 / 20$ & $20 / 20$ & 12.0 & 5.0 & 2.0 & $<1$ & 1.18 & & 1.15 & & 1.16 \\
\hline 21 & $M$ & 47 & $20 / 20$ & $20 / 20$ & 22.5 & 7.0 & 29.8 & & 1.01 & & 1.23 & & 1.12 \\
\hline 22 & $M$ & 36 & $20 / 20$ & $20 / 20$ & 18.0 & 3.0 & 20.0 & 1.6 & 1.20 & tritan & 1.25 & tritan & 1.23 \\
\hline 23 & $M$ & 37 & $20 / 20$ & $20 / 20$ & 6.0 & 10.0 & 134.7 & 3.3 & 1.25 & tritan & 1.59 & tritan & 1.42 \\
\hline 24 & $\mathrm{~F}$ & 42 & $20 / 25$ & $20 / 25$ & 7.0 & 13.0 & 50.0 & 4.2 & 1.26 & tritan & 1.33 & tritan & 1.30 \\
\hline Mean & & 41.63 & & & 10.6 & 6.4 & 40.6 & 2.7 & 1.08 & & 1.20 & & 1.14 \\
\hline (SD) & & $(6.46)$ & & & (5.2) & $(4.0)$ & (36.4) & (1.2) & $(0.13)$ & & $(0.17)$ & & $(0.14)$ \\
\hline Min & & 33 & & & 24.5 & 15.0 & 134.7 & 4.3 & 1.38 & & 1.66 & & 1.52 \\
\hline Max & & 54 & & & 4.0 & 1.0 & 1.2 & 1.0 & 1.00 & & 1.00 & & 1.00 \\
\hline
\end{tabular}

$I D$ = subject identification; $V A=$ visual acuity; $O D=$ oculum destrum; $O S$ = oculum sinistrum; Exp. = exposure duration; Away = time away from exposure to the mercury source; $\mathrm{Hg} 1$ = mean urinary concentration of $\mathrm{Hg}-\mu \mathrm{g} / \mathrm{g}$ creatinine - during exposure or up to 1 year thereafter; $\mathrm{Hg} 2=$ mean urinary concentration of $\mathrm{Hg}-\mu \mathrm{g} / \mathrm{g}$ creatinine - at the time of color vision testing or up to 1 year thereafter; Type = type of color vision defect; Mean of eyes $=$ mean of best and worst eyes. Mean (SD), minimum and maximum values for each column are reported at the bottom of the table. 
tenets of the Declaration of Helsinki and were approved by the Ethics Committees of the Institute of Psychology (190803) and of the University Hospital (378/03), University of São Paulo.

The D-15 and D-15d tests contain 16 color chips $1.2 \mathrm{~cm}$ in diameter in a black plastic support. The colors of each chip are defined by the Munsell system. The chips of the D-15 test have the same lightness (value $=5$ ) and saturation (chroma $=4$ ) while the chips of the D-15d test have a higher lightness (value $=8$ ) and lower saturation (chroma $=2$ ). The color chips were placed on a desk top covered with a black cloth. An illumination of 500 lux was provided by two fluorescent lamps (Sylvania Octron 6500 K FO32W/ 65K Day-Light, Munich, Germany) in an otherwise dark room.

The subject's eye was positioned $50 \mathrm{~cm}$ away from the color chips. The subjects were shown the chips in the test box in the correct chromatic order and allowed to inspect them. The chips were removed from the box, placed randomly on the desk top, and the subjects were instructed to return them to the box in the correct order. Subjects were first submitted to the D-15 test and then to the D- $15 \mathrm{~d}$ test, with the same instructions. The D-15d test was repeated up to three times and the best result was considered. The patients were tested monocularly in both eyes, and the controls in one eye, randomly chosen.

Total color distance score (TCDS) (13) was calculated for both tests. The minimum TCDS value for the correct order is 116.9 for the D-15 test and 56.41 for the D-15d test (Table 1). The higher the value, the worse is hue discrimination. In addition, we calculated the color confusion index $(\mathrm{CCI}=$ subject score/TCDS) whose minimum value is 1.0, and higher values indicate worse hue discrimination $(14,15)$. The statistical analysis was processed using the CCI parameter.

As is characteristically observed in acquired dyschromatopsias, the two eyes were affected differently and, therefore the analyses for the "best eye" and "worst eye" are presented for each test. We also calculated the "mean" of best eye and worst eye results.

For the D-15 test, TCDS (and CCI) results were $117.56 \pm 2.4(1.00 \pm 0.02)$ for the controls, and $117.66 \pm 1.96(1.00 \pm 0.02)$, best eye; $120.02 \pm 6.39(1.30 \pm 0.06)$, worst eye; $118.7 \pm 2.34(1.02 \pm 0.02)$, mean of eyes, for the patients. The Mann-Whitney U-test showed a significant difference between the two eyes of the patients $(\mathrm{P}<$ 0.001 ) and the worst eye of patients compared to controls $(\mathrm{P}=0.014)$ but not between the best eye of patients and controls $(\mathrm{P}=$ $0.630)$. The mean results of best and worst eyes for patients were also significantly different from controls $(\mathrm{P}=0.009$, Mann-Whitney U-test). The D-15 test was designed by Farnsworth in 1943 for screening congenital color vision deficiencies and is not a very sensitive test. Despite this limitation, there were differences between the best and worst eyes of the mercury-exposed subjects, revealing the asymmetry characteristic of acquired dyschromatopsia.

For the D-15d test, the TCDS (and CCI) were $58.8 \pm 3.53(1.04 \pm 0.06)$ for the controls, and $61.14 \pm 7.16(1.08 \pm 0.13)$, best eye; $67.29 \pm 17.32(1.22 \pm 0.18)$, worst eye; $64.30 \pm 7.71(1.14 \pm 0.14)$, mean of eyes, for the patients. The patients showed a difference between the two eyes $(\mathrm{P}<0.001)$, with scores significantly different from control scores for the worst eye $(\mathrm{P}=0.001)$, but not for the best eye $(\mathrm{P}=0.270)$. The mean of best and worst eyes was also significantly different $(\mathrm{P}=0.002$; Mann-Whitney U-test; Figure 1).

Although we did not detect a correlation between visual losses and time of exposure or time away from occupational exposure to mercury vapor $(\mathrm{P}>0.050)$, we performed a cluster analysis measuring the Euclidean distance in a complete linkage rule and found similarities among parameters of the color vision tests, time of exposure and time away 
from the environment. There was also no correlation between the color vision test results and the urinary mercury concentration (Table 1).

As we know from previous studies $(1,2)$ and as confirmed here, the D- $15 \mathrm{~d}$ test is more sensitive and appropriate than the D15 test for evaluating color discrimination in subjects occupationally exposed to neurotoxins. Since color vision losses are usually subclinical, and workers are unaware of any deficit, the D-15d test would be useful for screening color vision deficiencies in cases of early neurotoxicity in exposed workers.

These results confirm color vision losses reported for other groups of individuals exposed to metallic mercury: dentists, with chronic exposure at low levels (16), and gold miners (5). They also agree with reports of color vision impairment found in riverine communities exposed to methylmercury $(17,18)$.

The type of color vision losses was classified qualitatively by visual inspection of the line traces in the response charts. For this analysis, we considered those patients whose CCI in the D-15d test exceeded the confidence limit determined by the 95th percentile boundaries for controls, which corresponded to a value of $1.19($ TCDS $=67.32)$. For the best eye, $29.2 \%$ (7/24 eyes) of the patients had color vision defects, all classified with tritan losses. For the worst eye, $54.2 \%$ (13/24 eyes) of the patients had color vision defects as well as tritan losses. According to Paramei et al. (8), Kollner's rule indicates that tritan losses - in a toxic retinopathy - are present in outer retina dysfunction, and, in a more advanced stage, predominantly associated with high level and long-term exposure, the losses are diffuse with damage affecting the inner retina and optic nerve. Since we have no information about color vision during the time of exposure and these patients have been away from the occupational environment for more than one year, the damage of color discrimination may be irreversible for them.
These patients still present neuropsychological alterations due to mercury intoxication. Our study shows that, along with those symptoms, color vision losses are also present among the long-term effects of mercury intoxication.

Cavalleri and Gobba (19) suggested the reversibility of color vision losses based on a study of workers who had been exposed to metallic mercury, above the threshold level limits, and one year later - in a controlled occupational exposure condition, below the threshold level limits. The major difference between their study group and ours is the mean time of non-controlled occupational exposure. In their study, workers were exposed for 1 year while in our study they were exposed on average for 7 years (range: 4 to 24.5 years). To determine if the damage is in fact an irreversible color vision loss, it will be necessary to re-evaluate these patients during the next years.

There is no consensus about the reversibility of the color vision losses and its pathogenesis has not been elucidated $(19,20)$. The longterm losses found in this group of ex-workers

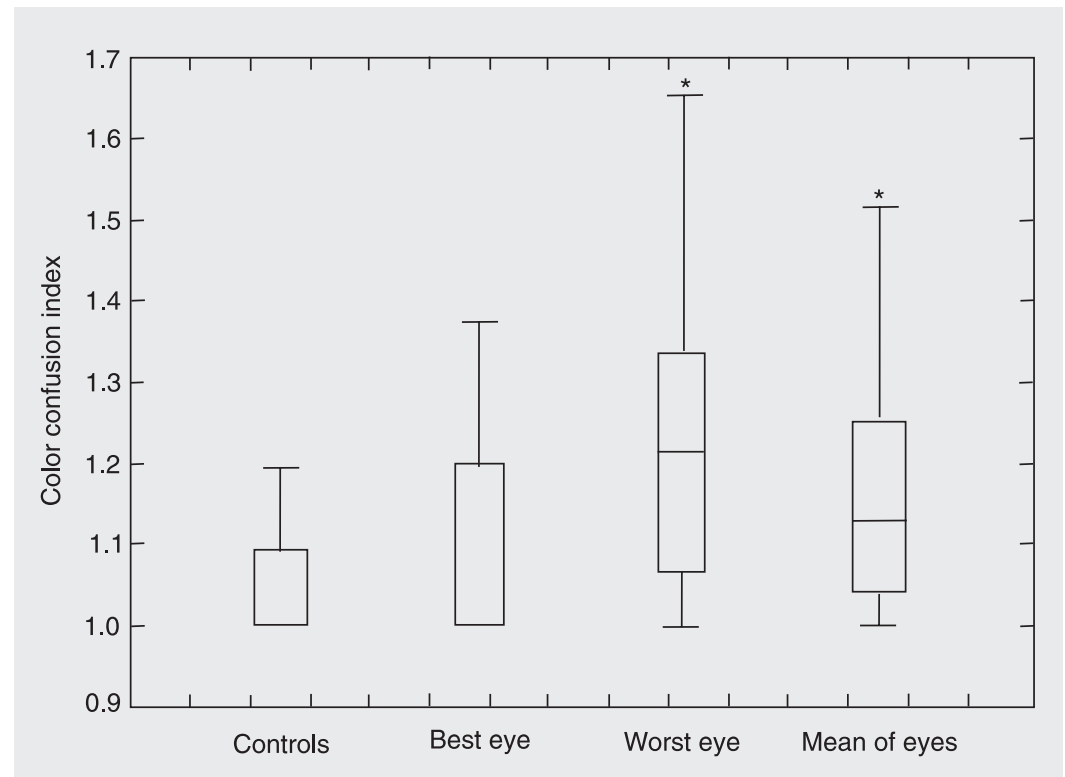

Figure 1. Color vision results obtained with the D-15d test. Color discrimination was statistically different from the controls for the worst eye and mean of eyes ( ${ }^{*} P<0.002$, Mann-Whitney U-test). 
indicate that the impairment in their color vision may not be reversible. A longitudinal study is needed to determine if the condition is stable, if it is deteriorating or improving. It is therefore necessary to perform more studies about the reversibility or not of the color vision defects in metallic mercury intoxication due to chronic exposure.

\section{Acknowledgments}

We thank Dr. Marcilia Medrado Faria, Department of Legal and Occupational Medicine, Oscar Freire Institute, University of São Paulo, for referring the patients for this study. We also thank Camila Perina for help with data collection.

\section{References}

1. Gobba F. Color vision: a sensitive indicator of exposure to neurotoxins. Neurotoxicology 2000; 21: 857-862.

2. Gobba F, Cavalleri A. Evolution of color vision loss induced by occupational exposure to chemicals. Neurotoxicology 2000; 21: 777-781.

3. Ventura DF, Costa MT, Costa MF, Berezovsky A, Salomão SR, Simões AL, et al. Multifocal and full-field electroretinogram changes associated with color-vision loss in mercury vapor exposure. Vis Neurosci 2004; 21: 421-429.

4. Ventura DF, Simões AL, Tomaz S, Costa MF, Lago M, Costa MTV, et al. Color vision and contrast sensitivity losses of mercury intoxicated industry workers in Brazil. Environ Toxicol Pharmacol 2006; 19: $523-529$.

5. Silveira LCL, Damin ETB, Pinheiro MCN, Rodrigues AR, Moura ALA, Côrtes MIT, et al. Visual dysfunction following mercury exposure by breathing mercury vapour or by eating mercury-contaminated food. In: Mollon JD, Pokorny J, Knoblauch K (Editors), Normal and defective colour vision. Oxford: Oxford University Press; 2006. p 407-417.

6. Lanthony P. The desaturated panel D-15. Doc Ophthalmol 1978; 46: 185-189.

7. Lanthony P. Evaluation of the desaturated Panel D-15. I. Method of quantification and normal scores. J Fr Ophtalmol 1986; 9: 843-847.

8. Paramei GV, Meyer-Baron M, Seeber A. Impairments of colour vision induced by organic solvents: a meta-analysis study. Neurotoxicology 2004; 25: 803-816.

9. Farnsworth D. The Farnsworth-Munsell 100-hue-test for the examination of colour discrimination manual. Baltimore: Munsell Color Company; 1957.

10. Birch J. Diagnosis of defective colour vision. Oxford: Butterworth Heinmann; 2001.
11. Meyer-Baron M, Schaeper M, Seeber A. A meta-analysis for neurobehavioural results due to occupational mercury exposure. Arch Toxicol 2002; 76: 127-136.

12. Hunter D, Russell DS. Focal cerebellar and cerebellar atrophy in a human subject due to organic mercury compounds. I Neurol Neurosurg Psychiatry 1954; 17: 235-241.

13. Geller AM. A table of color distance scores for quantitative scoring of the Lanthony desaturate color vision test. Neurotoxicol Teratol 2001; 23: 265-267.

14. Bowman KJ. A method for quantitative scoring of the Farnsworth Panel D-15. Acta Ophthalmol 1982; 60: 907-916.

15. Vingrys AJ, King-Smith PE. A quantitative scoring technique for panel tests of color vision. Invest Ophthalmol Vis Sci 1988; 29: 5063.

16. Canto-Pereira LHM, Lago M, Costa MF, Rodrigues AR, Saito C, Silveira LCL, et al. Visual impairment in dentists related to occupational mercury exposure. Environ Toxicol Pharmacol 2005; 19: 517522.

17. Rodrigues AR, Botelho de Souza CR, Rodrigues PSS, Silveira AT, Cortes MIT, Castro AJO, et al. Visual dysfunction following mercury exposure - necessity of norms for Amazonian populations. Proceedings of the International Workshop on Health and Environmental Effects of Mercury - Impacts of Mercury in South and Central America. December 2-3; Belém; 2003.

18. Silveira LCL, Ventura DF, Pinheiro MCN. Toxicidade Mercurial Avaliação do sistema visual em indivíduos expostos a níveis tóxicos de mercúrio. Cienc Cult 2003; 56: 36-38.

19. Cavalleri A, Gobba F. Reversible color vision loss in occupational exposure to metallic mercury. Environ Res 1998; 77: 173-177.

20. Gobba F, Cavalleri A. Color vision impairment in workers exposed to neurotoxic chemicals. Neurotoxicology 2003; 24: 693-702. 